\title{
Chamaejasmin B exerts anti-MDR effect in vitro and in vivo via initiating mitochondria-dependant intrinsic apoptosis pathway
}

This article was published in the following Dove Press journal:

Drug Design, Development and Therapy

22 September 2015

Number of times this article has been viewed

\author{
Ya Jie Wang' \\ Qi Li' \\ Hong Bin Xiao' \\ Yu Jie $\mathrm{Li}^{\prime}$ \\ Qing Yang' \\ Xiao Xi Kan' \\ Ying Chen' \\ Xiao Ni Liu ${ }^{2}$ \\ Xiao Gang Weng' \\ Xi Chen' \\ Wei Yan Cai' \\ Yan Guo' \\ He Fei Huang' \\ Xiao Xin Zhu' \\ Institute of Chinese Materia \\ Medica, China Academy of Chinese \\ Medical Sciences, ${ }^{2}$ Beijing Institute \\ of Hepatology and Beijing Youan \\ Hospital, Capital Medical University, \\ Beijing, People's Republic of China
}

Correspondence: Xiao Xin Zhu Institute of Chinese Materia Medica, China Academy of Chinese Medical Sciences, Beijing 100700, People's

Republic of China

Tel+861064056154

Email zhuxx59@I63.com

\begin{abstract}
Multidrug resistance (MDR) is the main obstacle limiting the efficacy of cancer chemotherapy. Looking for novel anti-MDR agents is an important way to conquer cancer drug resistance. We recently established that chamaejasmin B (CHB), a natural biflavone from Stellera chamaejasme L., is the major active component. However, its anti-MDR activity is still unknown. This study investigated the anti-MDR effect of CHB and the underlying mechanisms. First, it was found that $\mathrm{CHB}$ inhibited the growth of both sensitive and resistant cell lines in vitro, and the average resistant factor (RF) of CHB was only 1.26. Furthermore, $\mathrm{CHB}$ also displayed favorable anti-MDR activity in KB and KBV200 cancer cells xenograft mice. Subsequent study showed that CHB induced G0/G1 cell cycle arrest as well as apoptosis both in KB and in resistant KBV200 cancer cells. Further studies showed that CHB had no influence on the level of Fas/FasL and activation of procaspase 8 . However, CHB-induced apoptosis was dependent on the activation of caspase 9 and caspase 3. Moreover, $\mathrm{CHB}$ treatment resulted in the elevation of the $\mathrm{Bax} / \mathrm{Bcl}-2$ ratio, attenuation of mitochondrial membrane potential $\left(\Delta \Psi_{\mathrm{m}}\right)$, and release of cytochrome c and apoptosis-inducing factor from mitochondria into cytoplasm both in KB and KBV200 cells. In conclusion, CHB exhibited good anti-MDR activity in vitro and in vivo, and the underlying mechanisms may be related to the activation of mitochondrial-dependant intrinsic apoptosis pathway. These findings provide a new leading compound for MDR therapy and supply a new evidence for the potential of CHB to be employed in clinical trial of MDR therapy in cancers.
\end{abstract}

Keywords: drug resistance, chamaejasmin B, apoptosis, anticancer, Bax/Bcl-2

\section{Introduction}

Multidrug resistance (MDR), defined as the resistance of cancer cells to one chemotherapeutic drug accompanied by resistance to other chemotherapeutic drugs that may have different structures and mechanisms of action, is the major cause of failure in cancer chemotherapy. MDR is a complex phenomenon that can result from several biochemical mechanisms including altered membrane transport either by decreased drug uptake or by increased drug efflux, failure to undergo apoptosis, perturbed expression of target enzymes or altered target enzymes, altered drug activation or degradation, enhanced DNA repair, and so on. ${ }^{1-3}$ It is well known that the induction of apoptosis is one of the main mechanisms by which chemotherapeutic agents eradicate tumor cells, so the aberrant alteration at the level of apoptosis control is an important mechanism of MDR. According to MDR therapeutics, MDR reversal agents could increase the sensitivity of drugs to resistant cancer cells by influencing the function of drug transporters. However, anti-MDR agents could overcome cancer MDR by directly inhibiting the growth of cancer cells with MDR phenotype. ${ }^{4}$ In recent years, the development of novel anti-MDR agents has attracted more and more interests. Through thousands of 
years of research and practice, traditional Chinese medicine (TCM) has provided valuable material resources and a good foundation for investigating novel agents to handle MDR.

Resistance to apoptosis may result from aberrant ratio between pro-apoptotic and anti-apoptotic factors or from reinforcement of survival pathways. ${ }^{5,6}$ Regulation of ratio between pro-apoptosis and anti-apoptosis signaling pathway has become an important strategy to overcome MDR. It is well known that apoptosis often occurs through two broad pathways: the intrinsic mitochondrial or extrinsic death receptor pathway. ${ }^{7}$ In the intrinsic mitochondrial pathway, death stimuli is targeted to mitochondria either directly or through transduction by members of the Bcl-2 family and ultimately leads to caspases (such as caspase 9) activation and apoptosis. ${ }^{8,9}$ At a genetic level, resistance to apoptosis ultimately involves the decreased expression of pro-apoptotic genes, such as Bax as well as the increased expression of anti-apoptotic Bcl-2 gene. ${ }^{10}$ For the extrinsic death receptor pathway, Fas ligand (FasL)-Fas system is the most important signal pathway in different cell types. Fas-FasL interaction leads to the receptors located at the cellular membrane recruit adaptor proteins such as initiator caspase 8 , triggering the activation of caspases to orchestrate apoptosis. ${ }^{11}$ The alteration of Fas and FasL expression level is also found to result in cancer drug resistance. ${ }^{12,13}$

The TCM has a large pharmacopeia that includes over 5,500 natural sources, $82.8 \%$ of which are plants. Stellera chamaejasme L., known as Rui Xiang Lang Du in TCM, is a perennial herb that is widespread in Mongolia, Tibet, and the northern parts of People's Republic of China. The root of this plant has been used to treat various diseases including solid tumors, scabies, tinea, stubborn skin ulcers, chronic tracheitis, and tuberculosis. ${ }^{14}$ In our previous study, more attention has been paid to the pharmacological screening of various extracts from $S$. Chamaejasme L. (ESCs) on different tumor cells. As a result, ESC-2, the most potent extract, was found to exert good antitumor effect in vitro and in vivo, and the its antitumor activity is associated with causing apoptosis. ${ }^{15-19}$ In addition, it was found that the main functional constituents of ESC were biflavonoids, which have attracted more and more interests in treating solid tumors recently. ${ }^{20-23}$ For example, Neochamaejasmin B can inhibit the effect of P-glycoprotein ${ }^{24}$ and chamaejasmin B (CHB) exerted potent antiproliferative effects in eight human solid tumor cell lines. ${ }^{25}$ Consistently, recent study in our group has shown that CHB is the major potent cytotoxic biflavonoid from $S$. chamaejasme L. to exert antitumor activity, ${ }^{25,26}$ but whether it has the same activity toward resistant cells is still uncertain and the underlying mechanism remains to be determined. So here, we further evaluate the anti-MDR activity of $\mathrm{CHB}$ in vitro and in vivo, and investigate its effect on cellular apoptosis pathways both in sensitive and resistant cancer cells.

\section{Materials and methods Chemicals}

CHB was kindly provided by Prof Hong Bin Xiao (China Academy of Chinese Medical Sciences, Beijing, People's Republic of China). CHB is a light gray powder with $\geq 99.0 \%$ purity, which enables its use in HPLC, and is prepared freshly by dissolving in dimethyl sulfoxide (DMSO; Amresco, Solon, $\mathrm{OH}, \mathrm{USA}$ ) before use. The final concentration of DMSO was $0.1 \% \mathrm{v} / \mathrm{v}$. The chemical structure is shown in Figure 1A. Molecular formula is $\mathrm{C}_{32} \mathrm{H}_{26} \mathrm{O}_{10}$ and molecular weight is 570 . Z-LEDH-FMK, a caspase 9 inhibitor, was purchased from BD Biosciences (San Jose, CA, USA). Paclitaxel (TAX), doxorubicin (DOX), vincrinstine (VCR), 5-fluorouracil (5-FU), 1-(4,5-dimethylthiazol-2-yl)-3,5-diphenyformazan (MTT), and other chemicals were purchased from SigmaAldrich Co. (St Louis, MO, USA).

\section{Cell lines and cell culture}

The drug-resistant cell lines A549/tax and Bel7402/5-FU were generously provided by Dr Qian Liu (Peking Union
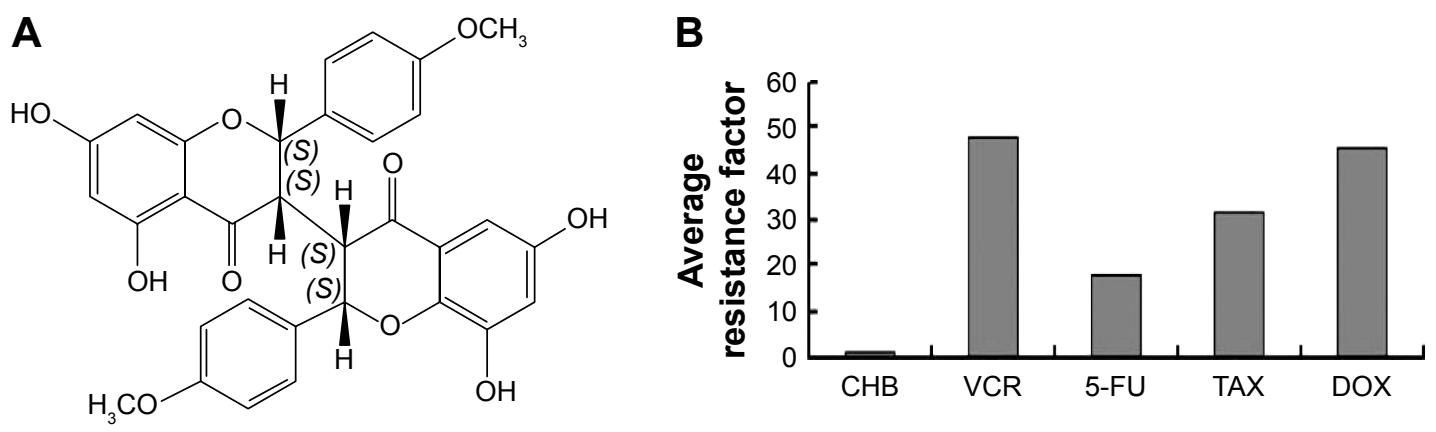

Figure I CHB exerts anti-MDR activity in vitro.

Notes: (A) Chemical structure of $\mathrm{CHB}$; (B) average resistance factors of $\mathrm{CHB}$ and four reference agents.

Abbreviations: CHB, chamaejasmin B; MDR, multidrug resistance; TAX, paclitaxel; DOX, doxorubicin; VCR, vincrinstine; 5-FU, 5-fluorouracil. 
Medical College, Beijing, People's Republic of China). Other parent cancer cell lines were kept in our group. Cells were cultured in RPMI1640 Medium (Thermo Fisher Scientific, Waltham, MA, USA) supplemented with $10 \%$ fetal bovine serum (HyClone, Logan, UT, USA) under standard conditions. To maintain drug resistance, $200 \mathrm{nM}$ VCR, $500 \mathrm{nM}$ DOX, $10 \mathrm{nM}$ TAX, and $150 \mathrm{nM}$ 5-FU were added to the culture of KBV200, MCF-7/dox, A549/tax, and Bel7402/5-FU cells, respectively. All experiments were performed after 7 days of incubation in drug-free medium. No ethics statement was required from the institutional review board for the use of these cell lines.

\section{Cytotoxicity assay}

Cell viability was assessed with MTT assay as previously described. ${ }^{27}$ Various concentrations of CHB were added into wells and incubated for 72 hours. $\mathrm{IC}_{50}$ value was defined as the drug concentration that inhibits $50 \%$ cell growth compared with the untreated controls and was calculated by Graphpad Prism 6.0 software. In addition, average resistant factors (RFs) of CHB and references were calculated according to the following equation:

$$
\text { Resistant factor }=\frac{\mathrm{IC}_{50}(\text { corresponding resistant cells })}{\mathrm{IC}_{50}(\text { parental cells })}
$$

\section{DAPI staining assay}

$\mathrm{KB}$ and KBV200 cells were cultured in 24-well plates and treated with different concentrations of CHB for 24 hours. The cells were fixed and washed, and then 4',6-diamidino2-phenylindole (DAPI, $1 \mu \mathrm{g} / \mathrm{mL}$ ) was added to the cells for 5 minutes. Cell nucleus was observed under fluorescence microscope.

\section{Annexin $\mathrm{V}$-propidium iodide binding assay} Apoptotic cells were differentiated from viable or necrotic cells using Annexin V-FITC Apoptosis Detection Kit (KeyGEN Biotech Inc., Nanjing, People's Republic of China). Briefly, after 24 hours of treatment with CHB, KB and KBV200 cells were harvested and $5 \mu \mathrm{L}$ of Annexin V-fluorescein isothiocynate (FITC) and $5 \mu \mathrm{L}$ of propidium iodide (PI) were added to the cells and kept for 10 minutes in the dark at room temperature. Flow cytometry analysis was performed using a fluorescence activated cell sorter (FACS; Beckman Coulter Inc., Pasadena, CA, USA).

\section{Cell cycle analysis}

After 24 hours of exposure to $\mathrm{CHB}$ at $6.25 \mu \mathrm{g} / \mathrm{mL}, \mathrm{KB}$ and KBV200 cells were washed and fixed with iced $70 \%$ ethanol and kept at $4^{\circ} \mathrm{C}$ overnight. Then, cells were collected and resuspended in phosphate-buffered saline (PBS) containing RNase A $(50 \mu \mathrm{g} / \mathrm{mL})$ for 30 minutes at $37^{\circ} \mathrm{C}$, followed by 30 minutes of treatment with PI $(50 \mu \mathrm{g} / \mathrm{mL})$ at $37^{\circ} \mathrm{C}$. After washing and resuspending the cells in PBS, the fluorescence activity of the cells was analyzed by a FACS (Beckman Coulter Inc.,).

\section{Mitochondrial membrane potential assay}

Mitochondrial membrane potential $\left(\Delta \Psi_{\mathrm{m}}\right)$ was analyzed by JC-1 (5,5',6,6'-tetrachloro-1,1',3,3'-tetraethylimidacarbocyanine iodide) mitochondrial Membrane Potential Assay Kit (KeyGEN Biotech Inc.). KB and KBV200 cells were treated with desired concentrations of CHB for 24 hours. Approximately, $1 \times 10^{6}$ cells were collected and incubated for 20 minutes in freshly prepared JC-1 solution at $37^{\circ} \mathrm{C}$. The cell-associated fluorescence was measured with a FACS (Beckman Coulter).

\section{Measurement of cytochrome $\mathrm{c}$ and AIF release}

After treatment with $\mathrm{CHB}$ as mentioned earlier, $\mathrm{KB}$ and KBV200 cells were collected and resuspended in Mito-Cyto extraction buffer provided by the Mitochondria/Cytosol Fractionation Kit (Applygen Technologies, Beijing, People's Republic of China), and kept on ice for 30 minutes. The cell suspension was added to a Dounce homogenizer and homogenized for 30 strokes on ice. The cell lysate was then centrifuged at $800 \times g$ for 5 minutes at $4^{\circ} \mathrm{C}$ to pellet the nucleus and cell debris. The supernatant was collected and centrifuged at $800 \times g$ for 5 minutes at $4^{\circ} \mathrm{C}$ again to thoroughly pellet the nucleus and cell debris. The supernatant was collected and centrifuged at $12,000 \times g$ for 10 minutes at $4^{\circ} \mathrm{C}$ to pellet mitochondria. Mitochondria were kept in an ice bath during the isolation process. The supernatant containing cytosol protein was separated by sodium dodecyl sulfate (SDS)-polyacrylamide gel electrophoresis (PAGE). The mitochondrial pellet was lysed in nondenaturing lysis buffer (Applygen Technologies Inc.) for 30 minutes on ice, centrifuged at $12,000 \times g$ for 15 minutes at $4^{\circ} \mathrm{C}$. The supernatant containing mitochondrial protein was analyzed by SDS-PAGE.

\section{Western blot analysis}

Western blot analysis was carried out as described previously. ${ }^{27}$ The membrane was immunoblotted with mouse monoclonal antibody to caspase $3(1: 1,000)$, caspase 9 (1:500), mouse monoclonal antibody to Bax and Bcl-2 (1:500), 
rabbit polyclonal to Fas and FasL (1:500), rabbit polyclonal to $\beta$-actin $(1: 1,000)$, rabbit polyclonal to AIF (1:500) (Santa Cruz Biotechnology, Santa Cruz, CA, USA), rabbit polyclonal to active capase $3(1: 1,000)$ (CST, Danvers, MA, USA), rabbit polyclonal to capase $8(1: 1,000)$, and rabbit polyclonal antibody to cytochrome c (1:500) (Bioworld Technology Inc., Nanjing, People's Republic of China). The membranes were finally developed using enhanced chemiluminescence (Fuji Film, Tokyo, Japan) reagent (Applygen Technologies Inc.) and exposed to film according to the manufacturer's protocol.

\section{Caspase 3 and caspase 9 activity assays}

The activity of caspase 3 and caspase 9 enzymes was measured in KBV200 after 24 hours of CHB treatment using standard kit (Applygen Technologies Inc.). The reaction mixture consisted of $30 \mu \mathrm{L}$ of cell extract protein, $65 \mu \mathrm{L}$ of reaction buffer, and $5 \mu \mathrm{L}$ of 2 mM DEVD-pNA (for caspase 3) or LEHD-pNA (for caspase 9) substrate in a total volume of $100 \mu \mathrm{L}$. The reaction mixture was incubated at $37^{\circ} \mathrm{C}$ for 7 hours, and the absorbance of the product was measured using microplate reader (ELX800; Bio-Tek Instruments, Inc, Winooski, VT, USA) at $405 \mathrm{~nm}$ according to the manufacturer's instruction.

\section{Mouse tumor xenografts and treatments}

Male BALB/c nude mice (Beijing Vital River Laboratory Animal Technology Co. Ltd, Beijing, People's Republic of China), at body weight of 18-20 g, were subcutaneously implanted with $1 \times 10^{7}$ parental KB or $3 \times 10^{7}$ resistant KBV200 cells, respectively. Tumors reached a mean group size of approximately $100 \mathrm{~mm}^{3}$, the mice with xenografts were randomly assigned to four groups ( $\mathrm{n}=8$ per group) including vehicle group (normal saline containing 1\% DMSO), VCR group ( $0.3 \mathrm{~g} / \mathrm{kg}), \mathrm{CHB}-\mathrm{L}$ group ( $1 \mathrm{mg} / \mathrm{kg}$ ), and CHB-H group ( $2 \mathrm{mg} / \mathrm{kg})$. The optimal dose was based on preliminary experiments as well as maximum tolerated dose. All agents were dissolved in sterile normal saline (containing 1\% DMSO) and injected intraperitoneally (ip) in a volume of $0.1 \mathrm{~mL} / 10 \mathrm{~g}$ body weight and the mice received various regimens once a day continuously for 19 days. Length and width of tumors were measured every 2 days, and the tumor volume $\left(\mathrm{mm}^{3}\right)$ was calculated by the formula, $\pi / 6 \times L \times W^{2}$, where length (L) and width (W) were determined in millimeters. The tumor sizes were standardized in different groups by using relative tumor volumes (RTV) calculated as: $\mathrm{RTV}=V n / V 0$, where $V n$ is the tumor volume at the day $n$ of the treatment and $V 0$ represents the initial tumor volume at the onset of treatment. Tumor measurements and body weight of the mice were recorded every other day. On day 19, the mice were sacrificed. The antitumor activity was assessed in terms of the $\mathrm{T} / \mathrm{C} \%$ and inhibitory rate (IR) of tumor weight. $\mathrm{T} / \mathrm{C} \%$ was defined as follows: $\mathrm{T} / \mathrm{C} \%=($ mean $\mathrm{RTV}$ of the treated group/mean RTV of the control group) $\times 100 \%{ }^{28}$ The curve of tumor growth was drawn according to RTV and treating time. In addition, tumors were excised from the mice and weighed. IR was calculated according to the following formula: IR $(\%)=1-$ (mean tumor weight of the experimental group/ mean tumor weight of the control group) $\times 100 \%$. All studies involving animals were conducted according to the welfare and ethical guidelines for experimental animal drafted by Beijing Experimental Animal Management Office and approved by the Committee for Control and Supervision of Experiments on Animals of Institute of Chinese Materia Medica, China Academy of Chinese Medical Sciences.

\section{Statistical analysis}

Data were indicated as mean \pm standard deviation (SD). Statistical analysis of the data was performed using one-way analysis of variance (ANOVA). $P<0.05$ was considered statistically significant.

\section{Results $\mathrm{CHB}$ displays potent anti-MDR activity in vitro}

We first tested the anti-MDR activity of CHB through four pairs of drug-sensitive cell lines and their MDR-sublines including KB, KBV200, A549, A549/tax, MCF-7, MCF-7/dox, Bel7402, and Bel7402/5-FU, as well as four kinds of traditional chemotherapeutics including VCR, TAX, DOX, and 5-FU. As shown in Table 1, CHB exerts a potent antiproliferative effect on both sensitive and resistant cells with $\mathrm{IC}_{50}$ values below $10 \mu \mathrm{g} / \mathrm{mL}$ after 72 hours of exposure. The RF of $\mathrm{CHB}$ to KBV200 cells was the lowest with a value of only 0.96 , which was much lower than that of the reference drug DOX $(\mathrm{RF}=18.09)$, VCR $(\mathrm{RF}=28.13)$, and TAX $(\mathrm{RF}=28.56)$. As shown in Figure 1B, the average RF of CHB was only 1.26, while that of VCR, 5-FU, TAX, and DOX was 47.98, $18.11,31.76$, and 45.6, respectively. Thus, compared with references, CHB displayed good anti-MDR activity in vitro. As the KB and KBV200 cells showed lowest RF values, they were employed as model cell lines to determine the underlying anti-MDR mechanism of CHB.

\section{CHB displays anti-MDR activity in vivo}

Based on anti-MDR activity in vitro, anti-MDR activity of $\mathrm{CHB}$ was further evaluated in vivo by establishing $\mathrm{KB}$ and KBV200 xenograft models. As shown in Figure 2 and Table 2, in VCR-treated KB xenograft model, the \% $\mathrm{T} / \mathrm{C}$ and IR were $23.67 \%$ and $71.21 \%$, respectively, while in KBV200 xenograft model they were $74.75 \%$ and $27.29 \%$, respectively. Thus it 
Table I Cytotoxicity of various agents against four pairs of resistant and sensitive cell lines

\begin{tabular}{|c|c|c|c|c|c|c|c|c|}
\hline & \multicolumn{8}{|c|}{$I C_{50}(\mu \mathrm{g} / \mathrm{mL})$} \\
\hline & KB & KBV200 & MCF-7 & MCF-7/Dox & A549 & A549/Tax & Bel7402 & Bel7402/5-Fu \\
\hline $\mathrm{CHB}$ & $6.62 \pm 0.47$ & $6.38 \pm 0.52$ & $7.52 \pm 2.96$ & $9.74 \pm 0.98$ & $6.56 \pm 0.97$ & $9.84 \pm 2.12$ & $3.21 \pm 1.30$ & $4.09 \pm 0.26$ \\
\hline VCR & $1.70 \pm 0.31$ & $47.83 \pm 9.92$ & $2.38 \pm 1.36$ & $319.14 \pm 16.89$ & $5.12 \pm 1.02$ & $106.82 \pm 27.1$ & $51.25 \pm 5.6 \mathrm{I}$ & $439.02 \pm 37.52$ \\
\hline TAX & $0.13 \pm 0.05$ & $3.57 \pm 1.64$ & $0.38 \pm 0.12$ & $14.415 \pm 1.14$ & $0.39 \pm 0.15$ & $18.32 \pm 5.44$ & $0.58 \pm 0.14$ & $7.84 \pm 1.7 \mid$ \\
\hline DOX & $0.97 \pm 0.06$ & $17.55 \pm 2.60$ & $0.49 \pm 0.04$ & $62.315 \pm 2.74$ & $0.92 \pm 0.35$ & $23.07 \pm 3.09$ & $0.62 \pm 0.34$ & $7.39 \pm 0.95$ \\
\hline 5-FU & $3.79 \pm 1.44$ & $|7.43 \pm 5.9|$ & $9.19 \pm 1.29$ & $208.89 \pm 58.29$ & $2.68 \pm 0.57$ & $10.06 \pm 0.37$ & $2.63 \pm 1.39$ & $108.89 \pm 6.29$ \\
\hline
\end{tabular}

Note: Data are mean \pm SD of at least three independent experiments.

Abbreviations: CHB, chamaejasmin B; TAX, paclitaxel; DOX, doxorubicin; VCR, vincrinstine; 5-FU, 5-fluorouracil; SD, standard deviation.

was implied that KBV200 xenograft model was resistant to VCR treatment. At the same time, both CHB-treated groups exhibited good anticancer activity in either KB or KBV200 xenograft model. Especially, in CHB-H group (2 mg/kg), the $\% \mathrm{~T} / \mathrm{C}$ and IR in KB xenograft model were $36.44 \%$ and $65.06 \%$, respectively, while in KBV200 xenograft model, they were $48.29 \%$ and $69.06 \%$, respectively. Notably, CHB also exerted good anti-MDR effect in vivo.

A

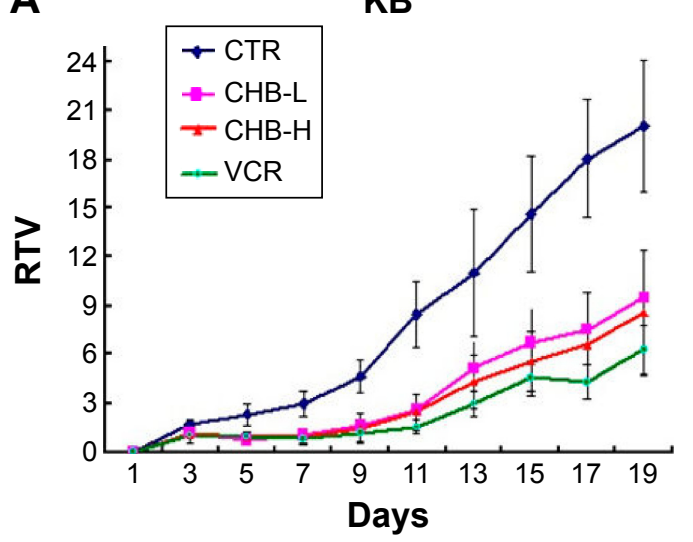

B

KBV200

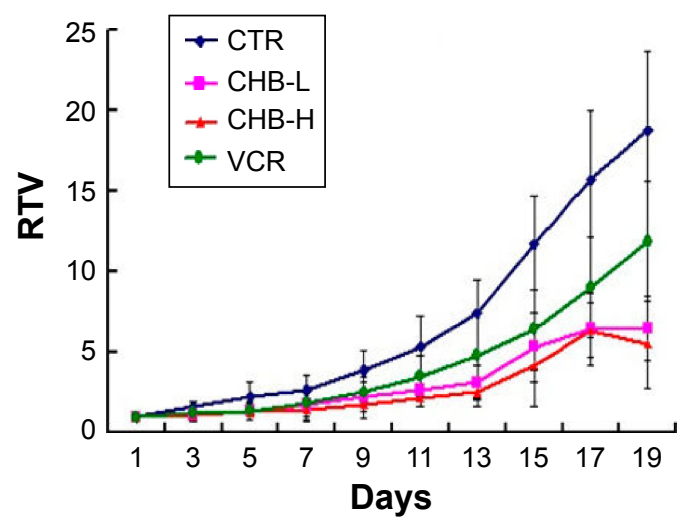

CHB causes G0/GI cell cycle arrest of KB and KBV200 cells

After the cells were exposed to $\mathrm{CHB}$ at $6.25 \mu \mathrm{g} / \mathrm{mL}$ for 24 hours, cell cycle distribution was analyzed using flow cytometry. As shown in Figure 3, compared to the control cells, the proportion of $\mathrm{G} 0 / \mathrm{G} 1$ phase increased from $62.66 \%$ to $79.07 \%$ and $61.23 \%$ to $81.22 \%$ after CHB treatment in $\mathrm{KB}$ and KBV200 cells, respectively. These results illustrated

C

KB

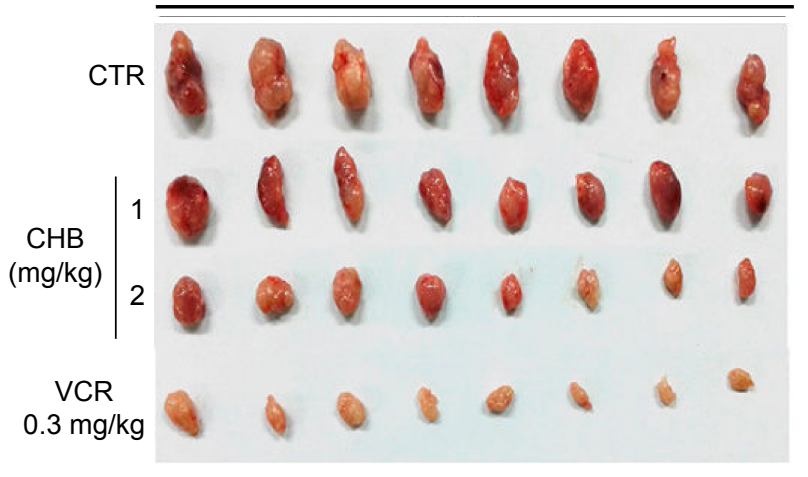

D KBV

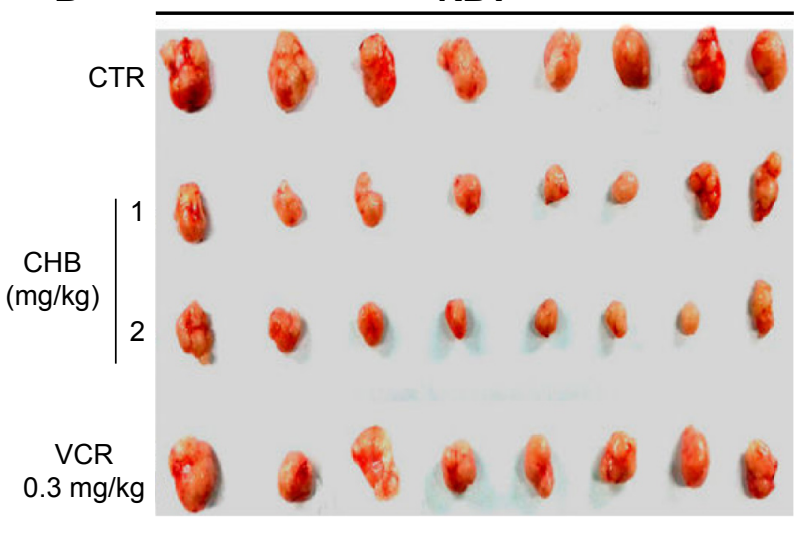

Figure $2 \mathrm{CHB}$ exerts anti-MDR activity in vivo.

Notes: (A, B) The xenograft experiment was carried out using nude mice implanted subcutaneously with KB or KBV200 cells under the right armpits. Data are mean \pm SD of the relative tumor volume for each group of eight experimental animals. (C, D) The picture shows the tumor size of KB and KBV200 xenograft at the end of the experiment.

Abbreviations: CTR, vehicle control group; CHB-L, I mg/kg group; CHB-H, 2 mg/kg group; VCR, vincrinstine group; CHB, chamaejasmin B; MDR, multidrug resistance; RTV, relative tumor volumes; SD, standard deviation. 
Table 2 Inhibiting effect of $\mathrm{CHB}$ on tumor growth of $\mathrm{KB}$ and $\mathrm{KBV} 200$ xenograft nude mice

\begin{tabular}{|c|c|c|c|c|c|c|c|}
\hline \multirow[b]{2}{*}{ KB } & \multirow{2}{*}{$\begin{array}{l}\text { Group } \\
\text { CTR }\end{array}$} & \multicolumn{2}{|c|}{$\begin{array}{l}\text { Number } \\
\text { (initial/end) }\end{array}$} & \multicolumn{2}{|c|}{$\begin{array}{l}\text { Body weight (g) } \\
\text { (initial/end) }\end{array}$} & \multirow{2}{*}{$\begin{array}{l}\begin{array}{l}\text { Tumor } \\
\text { weight (g) }\end{array} \\
1.53 \pm 0.21\end{array}$} & \multirow[t]{2}{*}{$\begin{array}{l}\text { Inhibition } \\
\text { rate (\%) }\end{array}$} \\
\hline & & 8 & 8 & $19.05 \pm 0.99$ & $21.21 \pm 2.03$ & & \\
\hline & CHB-L & 8 & 8 & $18.9 \mid \pm 0.66$ & $19.89 \pm 2.22$ & $0.81 \pm 0.16^{*}$ & 55.87 \\
\hline & $\mathrm{CHB}-\mathrm{H}$ & 8 & 8 & $18.97 \pm 0.98$ & $18.92 \pm 1.58$ & $0.53 \pm 0.16 *$ & 65.06 \\
\hline & VCR & 8 & 8 & $19.07 \pm 1.19$ & $19.05 \pm 2.30$ & $0.44 \pm 0.15^{*}$ & 71.21 \\
\hline \multirow[t]{4}{*}{ KBV200 } & CTR & 8 & 8 & $19.16 \pm 1.09$ & $21.26 \pm 1.38$ & $1.56 \pm 0.27$ & \\
\hline & CHB-L & 8 & 8 & $19.35 \pm 1.16$ & $20.37 \pm 1.20$ & $0.62 \pm 0.21 *$ & 60.02 \\
\hline & $\mathrm{CHB}-\mathrm{H}$ & 8 & 8 & $19.10 \pm 1.12$ & $18.84 \pm 1.77$ & $0.48 \pm 0.17 *$ & 69.06 \\
\hline & VCR & 8 & 8 & $19.5 \mid \pm 0.76$ & $19.02 \pm 1.63$ & I. $13 \pm 0.27 *$ & 27.29 \\
\hline
\end{tabular}

Notes: The experiment was carried out using nude mice implanted subcutaneously with KB or KBV200 cells under the right armpits. Animals were randomized into four groups including CTR (vehicle control), VCR (vincrinstine, $0.3 \mathrm{mg} / \mathrm{kg}$ ), CHB-L (Chamaejasmin B, I mg/kg), and CHB-H (Chamaejasmin B, $2 \mathrm{mg} / \mathrm{kg}$ ), ip, qd $\times 19$. At the end of the experiment, body weight was determined and tumor tissue was weighed. Data are mean $\pm S D$ of the tumor weight for each group of eight experimental animals. $* P<0.05$ vs control group.

Abbreviations: CHB, chamaejasmin; SD, standard deviation; ip, intraperitoneal; qd, every day.

that $\mathrm{CHB}$ causes $\mathrm{G} 0 / \mathrm{G} 1$ cell cycle arrest both in $\mathrm{KB}$ and KBV200 cells.

\section{$\mathrm{CHB}$ induces apoptosis of $\mathrm{KB}$ and KBV200 cells}

Cancer cells were exposed to increasing concentrations of CHB and the degree of apoptotic cell death was quantified with AnnexinV-FITC/PI double-labeled cytometry. As shown in Figure 4A, after the treatment of cells with CHB at 6.25, 12.5 , and $25 \mu \mathrm{g} / \mathrm{mL}$ for 24 hours, $\mathrm{CHB}$ could induce apoptosis in KB and KBV200 cells at a concentration-dependent manner. Additionally, apoptosis rate in KBV200 cells is a little more than that of $\mathrm{KB}$ cells at $25 \mu \mathrm{g} / \mathrm{mL}$ of $\mathrm{CHB}$ (Figure $4 \mathrm{C}$ and D). Consistent with the results obtained previously, DAPI staining showed that some of the CHB-treated cells exhibited highly condensed and fragmented nuclei morphology, which were the typical characteristics of apoptosis (Figure 4B, shown by arrowheads). All the phenomena were consistent with the anti-MDR activity observed in vitro.

\section{Apoptosis induced by $\mathrm{CHB}$ is not through extrinsic Fas/FasL pathway}

Fas is the well-known member of the tumor necrosis factor receptors superfamily, which activates apoptosis by recruiting a number of adaptor, signaling, and effector proteins. Expression of Fas receptor and its respective ligand (FasL) was detected by Western blot. As shown in Figure 4E, the level of neither Fas nor FasL was affected by 24 hours of treatment of CHB in both KB and KBV200 cells. Caspase 8 is the crucial initiator caspase in signal transmission by death receptor pathway. As shown in Figure 4E, the zymogen of procaspase 8 also did not change either in KB or in KBV200cells. These results suggest that the apoptosis induced by
CHB may not be through the Fas/FasL extrinsic pathway in $\mathrm{KB}$ and in KBV200 cells.

\section{Apoptosis induced by $\mathrm{CHB}$ is dependent on caspases 3 and 9 activation}

Caspase 9 is the main caspase member that mediates intrinsic apoptosis, while caspase 3 is a key effector caspase, responsible for cleaving large number of protein substrates. In order to investigate whether CHB triggered intrinsic apoptosis, the enzymatic activity of caspase 9 and caspase 3 was first detected in KBV200 cells. As shown in Figure 5A and B, the activity of caspases 9 and 3 was significantly enhanced in a concentration-dependant manner in KBV200 cells after 24 hours of CHB treatment. Similar results were obtained by Western blot in both KB and KBV200 cells (as shown in Figure $5 \mathrm{C}-\mathrm{G}$ ). To further investigate whether $\mathrm{CHB}$-induced apoptosis was caspase 9-dependent, the cells were pretreated with a cell-permeable caspase 9 inhibitor, Z-LEHD-FMK $(20 \mu \mathrm{M})$. As shown in Figure $5 \mathrm{H}-\mathrm{J}$, the ability of CHBinduced apoptosis was remarkably attenuated in $\mathrm{KB}$ and KBV200 cells after pretreatment with Z-LEHD-FMK. These results suggest that apoptosis induced by CHB is caspase 9-dependent.

\section{$\mathrm{CHB}$ triggers intrinsic mitochondrial apoptosis pathway}

Caspase 9 is a crucial initiator caspase in the signal transmission of mitochondrial apoptosis pathway. Bcl-2 family proteins can regulate the release of caspase 9. As shown in Figure $6 \mathrm{~A}-\mathrm{C}, 24$ hours of treatment of CHB significantly downregulated the expression of Bcl-2 and upregulated the expression of Bax. The collapse of $\Delta \Psi$ is an early event in the induction of apoptosis through the intrinsic mitochondrial 

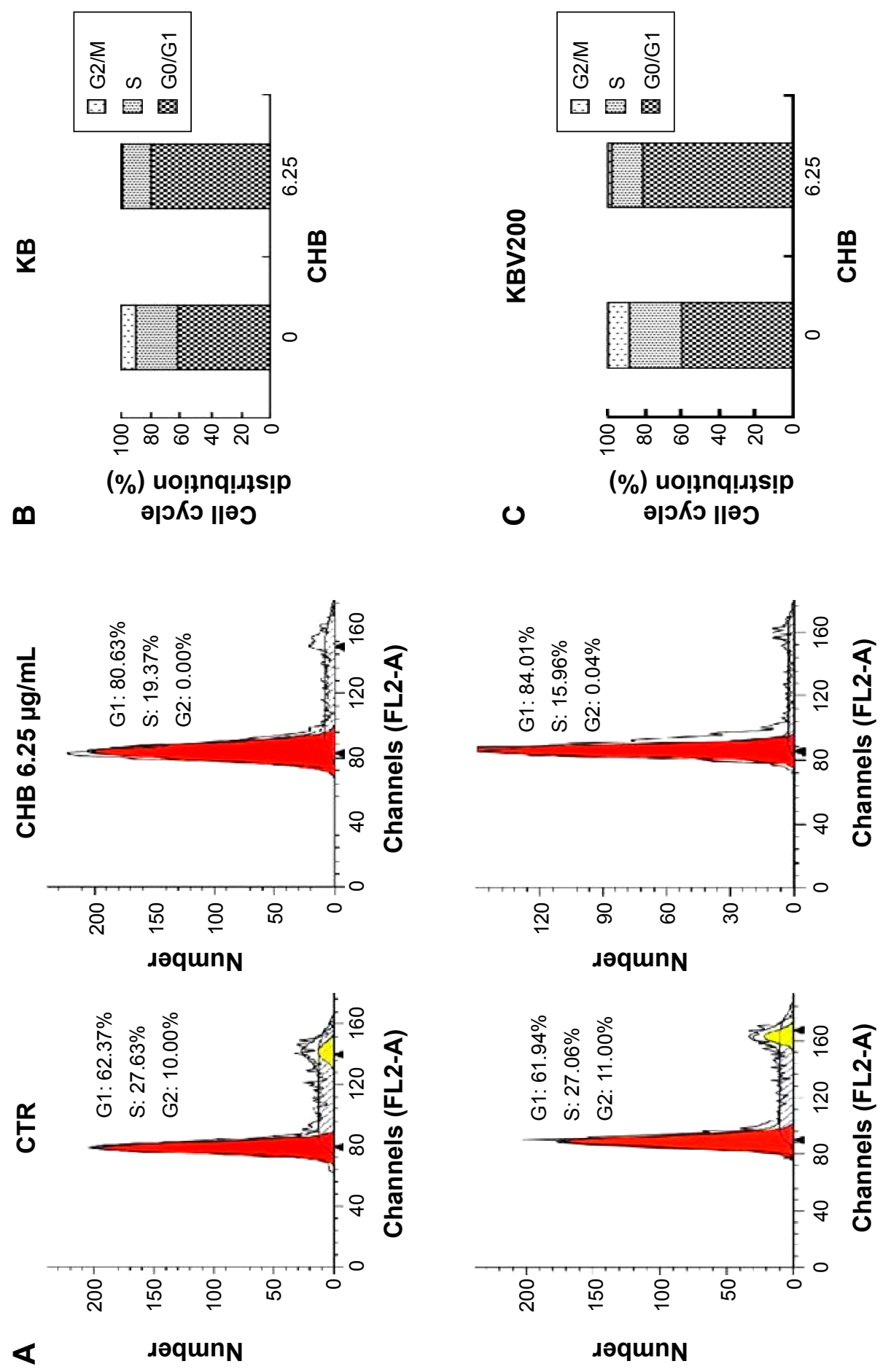

q

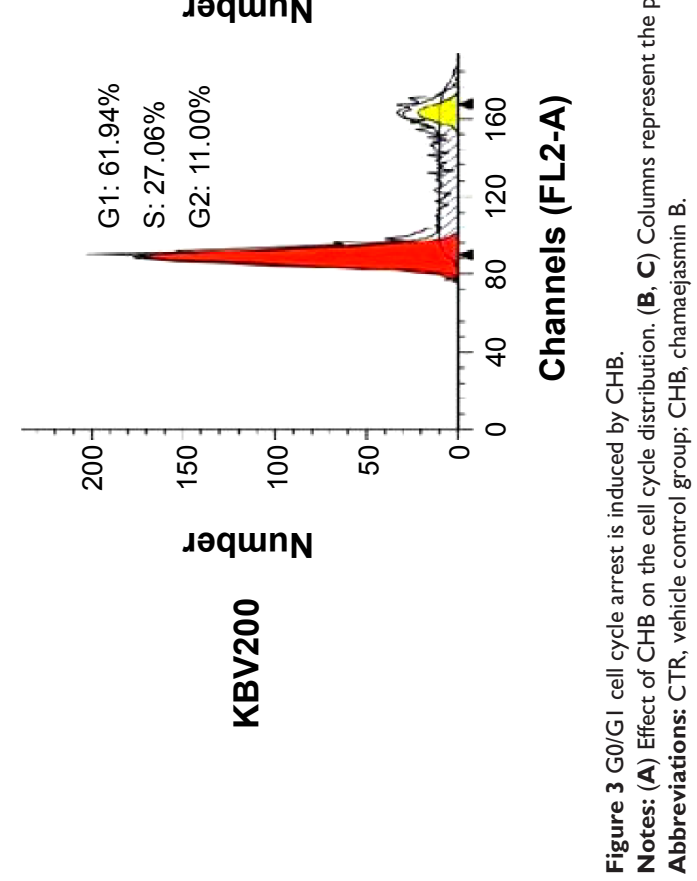



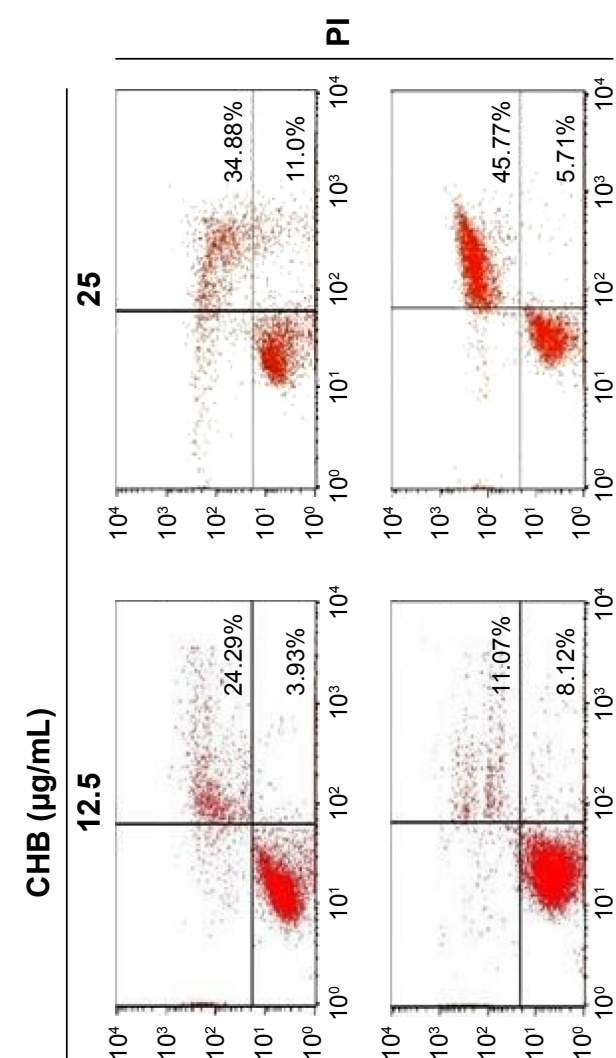

옳

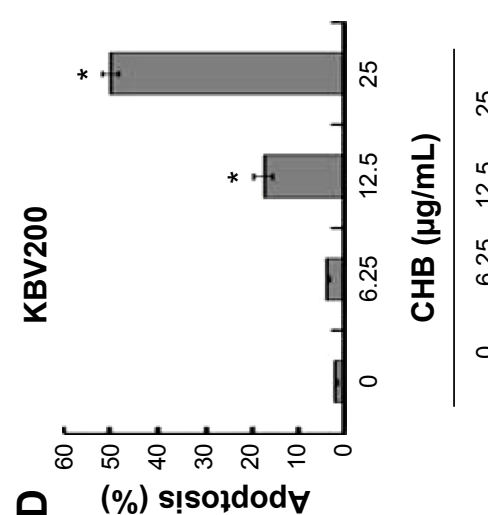

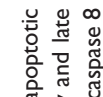

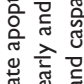

๑ $\quad(\%)$ s!soldod $\forall$
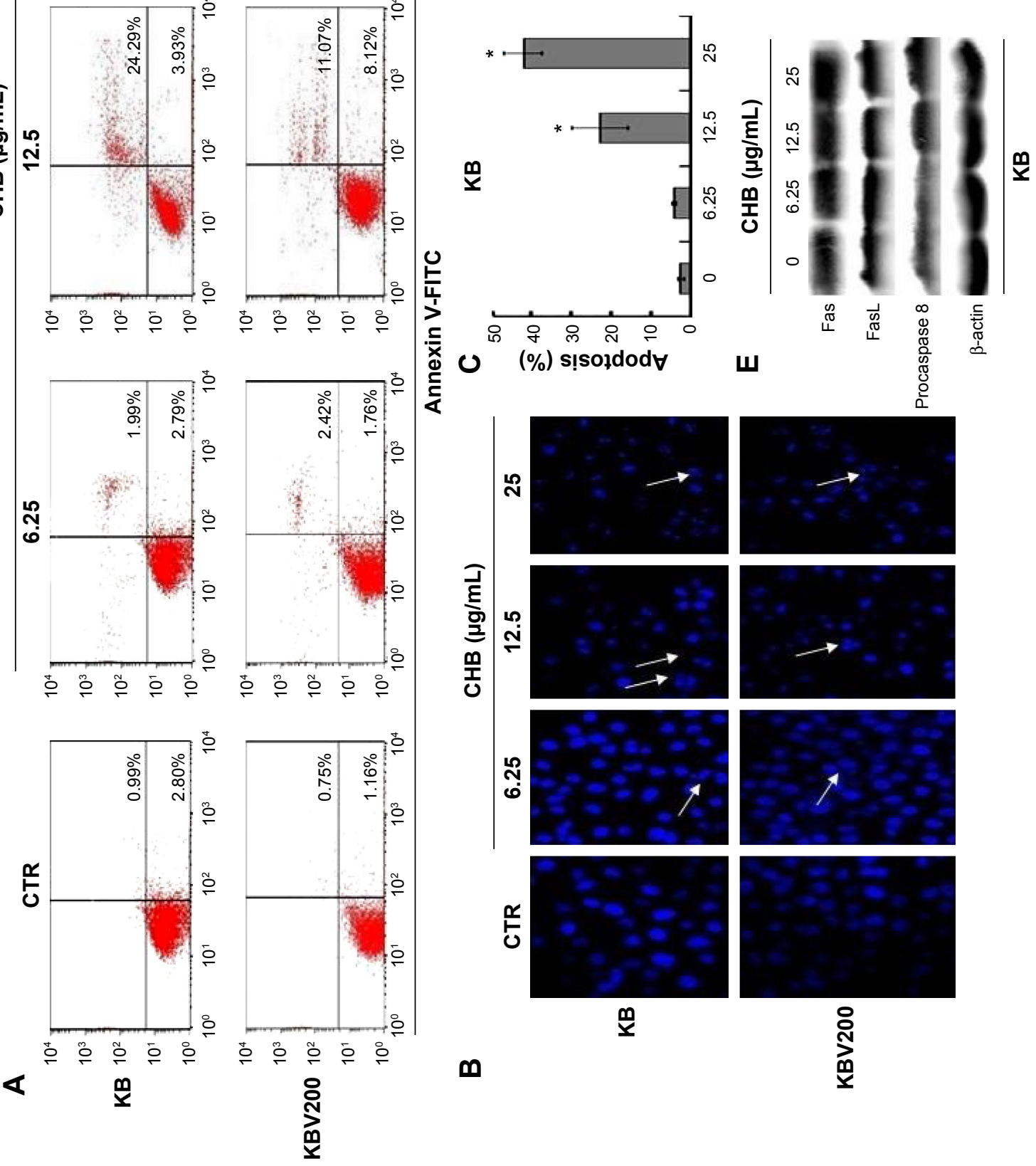

官

额 总

势

辛竞苛

表 券

这合

产京产

喜证

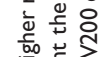

这这

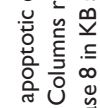

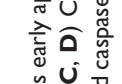

कृ

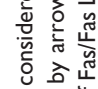

帘产

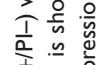

齐

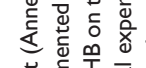

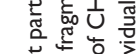

总芯芯

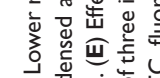

房言

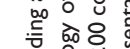

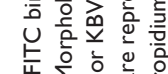

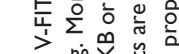

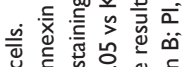

잉

空全各*

可证

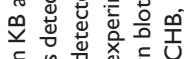

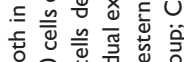

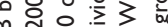

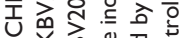

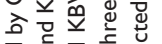

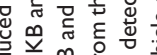

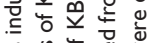

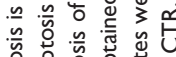

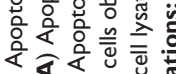

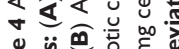

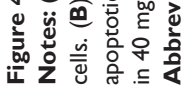



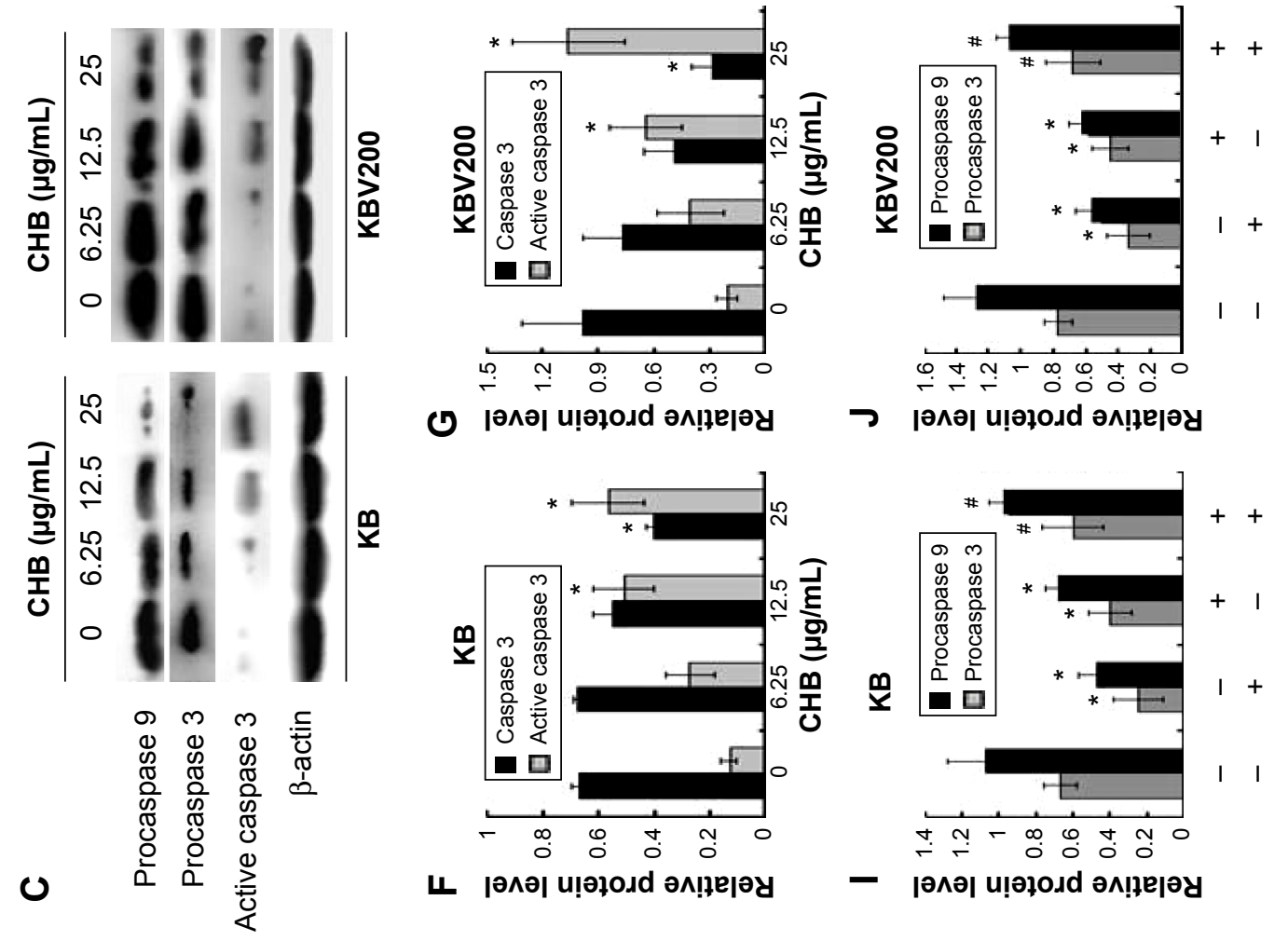

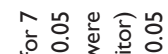

U.

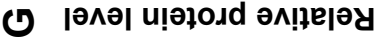

$\neg$ |әләр u!әнолd әм!ґе|әу
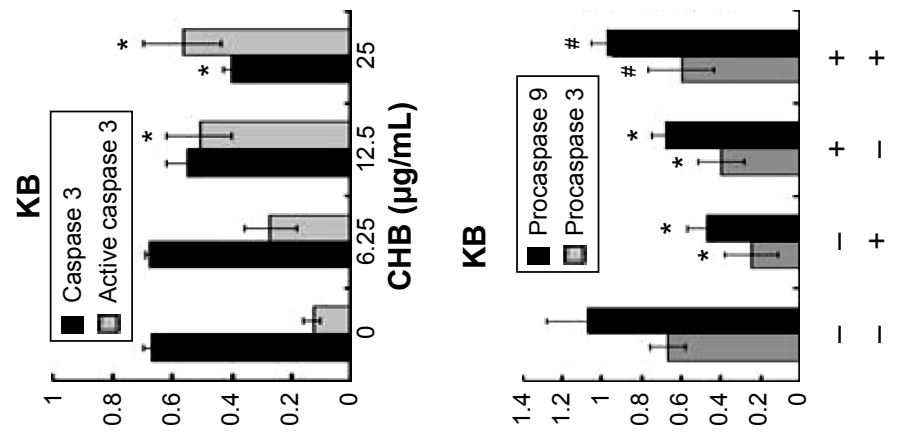

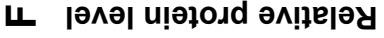

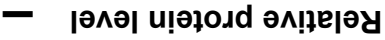

m
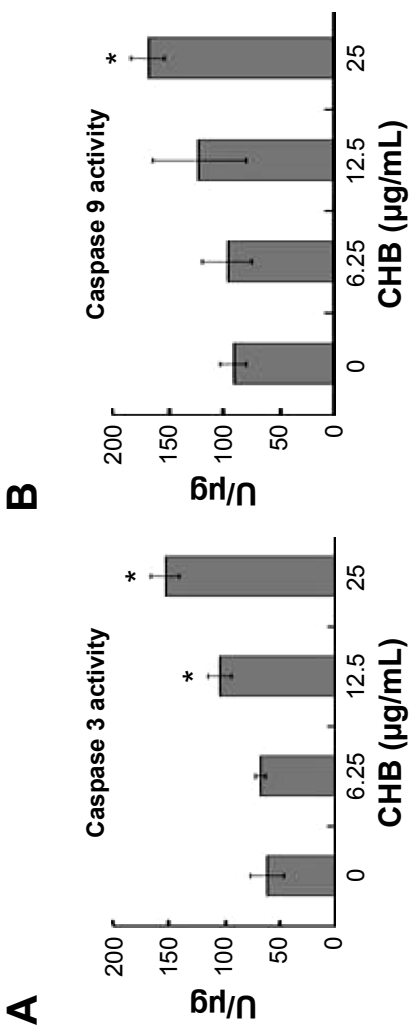

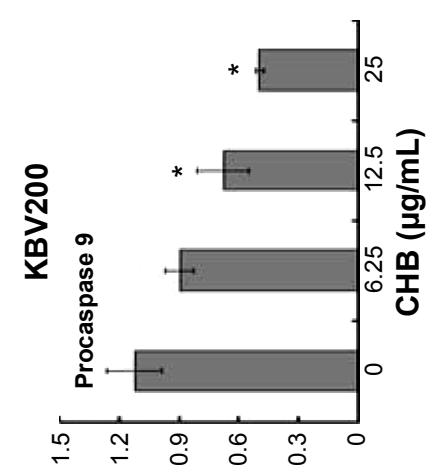

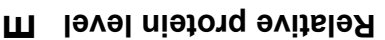
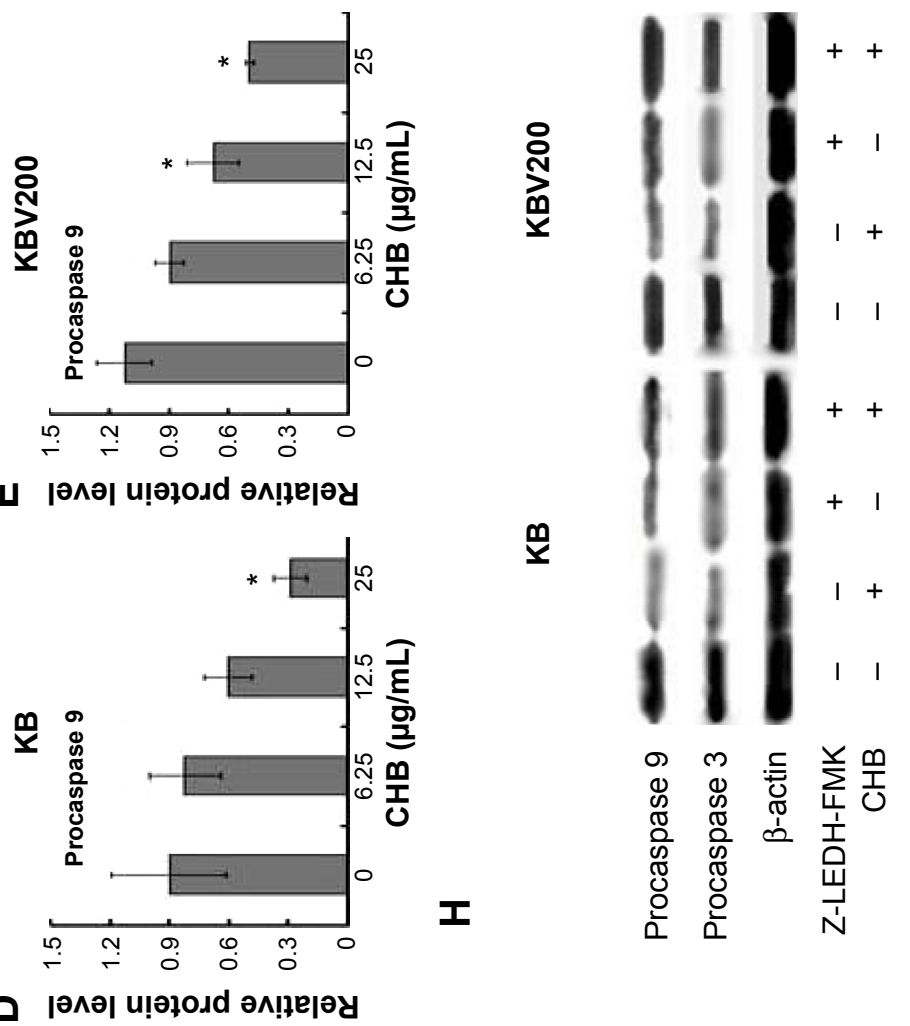

ठ․ำ

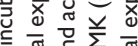

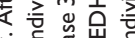

造造造

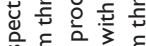

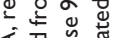

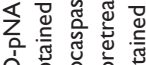

界要边

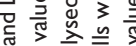

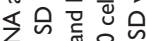

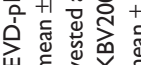

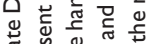

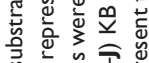

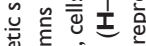

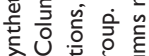

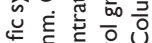

षूّ

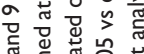

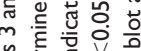

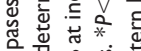

gू

等U

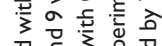

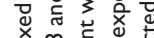

है

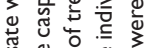

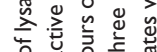

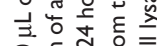

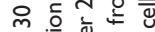

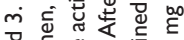

등월

yे

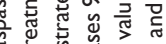

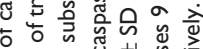

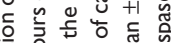

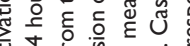

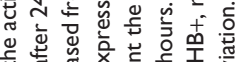

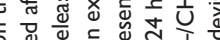

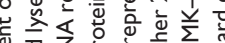

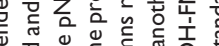

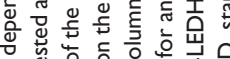

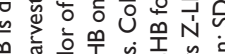

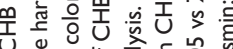

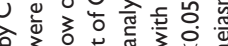

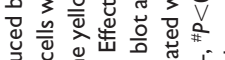

운

능

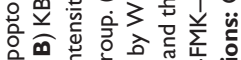

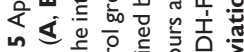

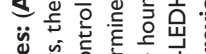



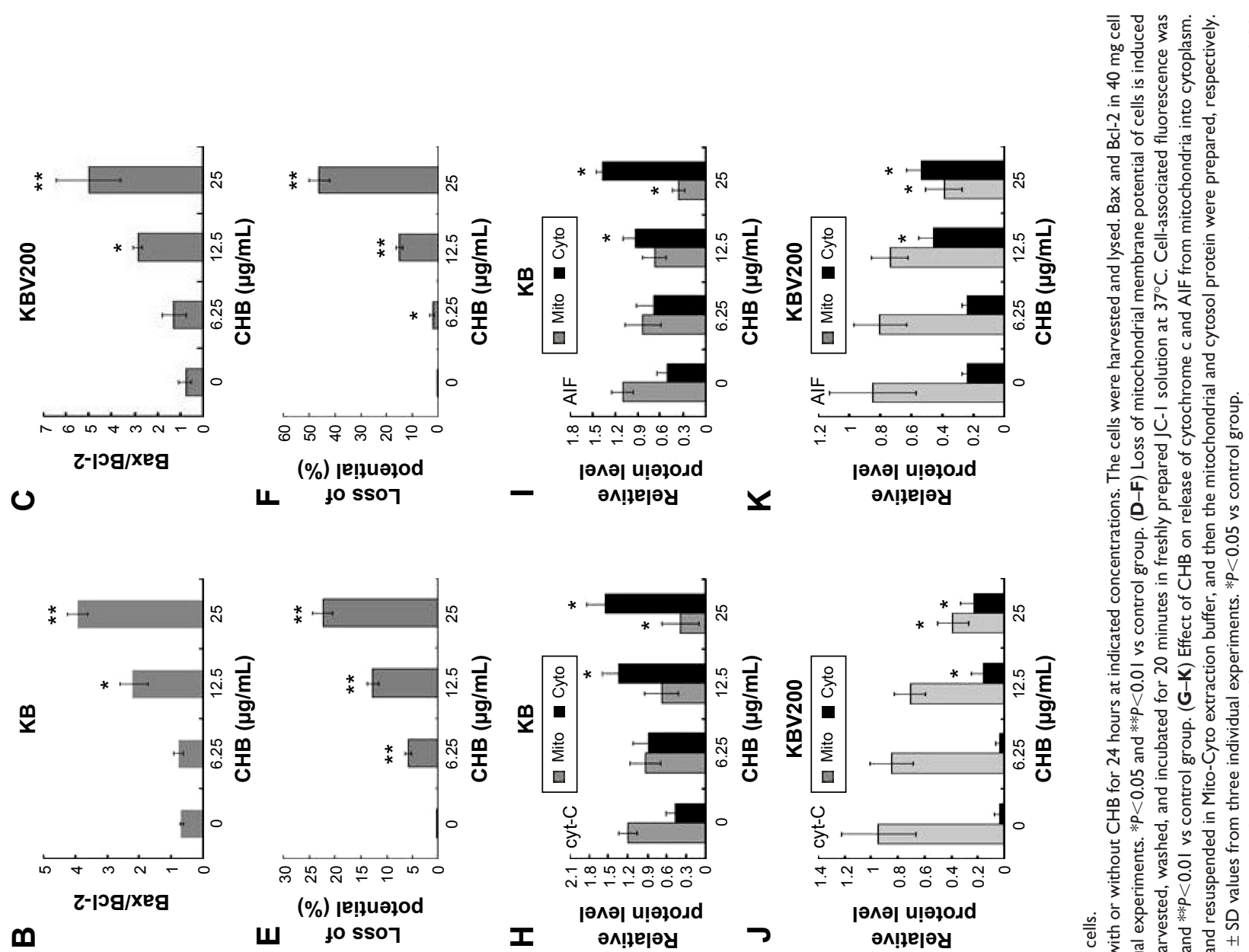

$\boldsymbol{m}$

山 to ssoา

I
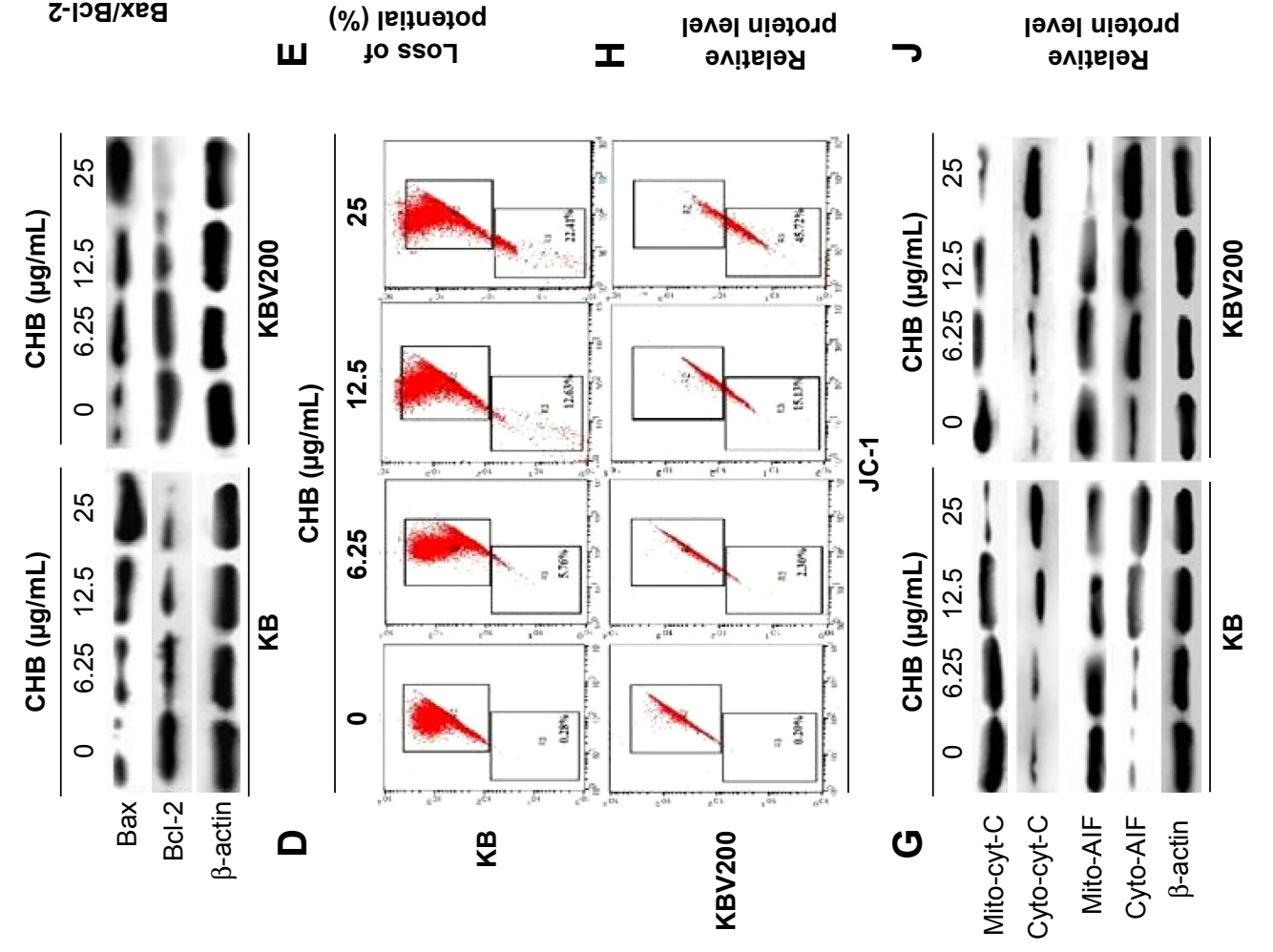

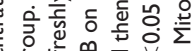

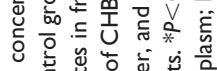

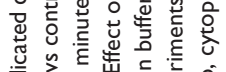

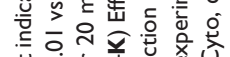

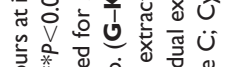

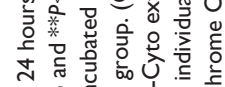

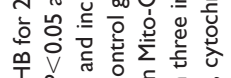

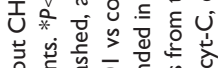

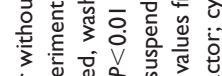

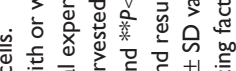

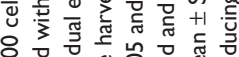

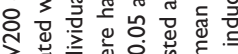

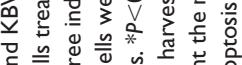

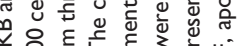

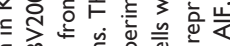

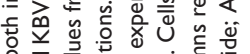

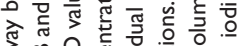

茲令

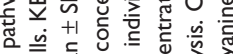

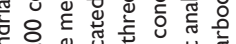

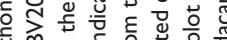

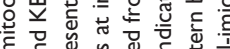

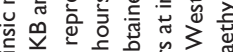

.气

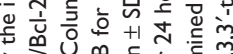

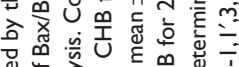

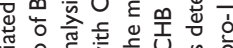

等.

है

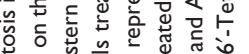

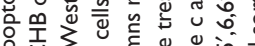

论

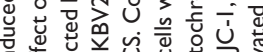

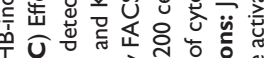

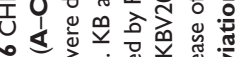

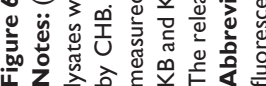


pathway. Thus the variation of $\Delta \Psi$ was further determined by JC-1 staining assay. In nonapoptotic cells, the dye accumulates and aggregates within the mitochondria, resulting in bright red staining (R2 area in Figure 6D). In apoptotic cells, due to the collapse of the membrane potential, the JC-1 cannot accumulate within the mitochondria and remains in the cytoplasm in its green fluorescent monomeric form (down in $\mathrm{R} 3$ area in Figure 6D). As indicated in Figure 6E and F, exposure to $6.25 \mu \mathrm{g} / \mathrm{mL}$ CHB for 24 hours caused $5.76 \%$ and $2.30 \%$ membrane potential collapse in KB and KBV200 cells, respectively, and the collapse was up to $22.41 \%$ and $45.72 \%$ in $\mathrm{KB}$ and KBV200 cells, respectively, after exposure to $25 \mu \mathrm{g} / \mathrm{mL} \mathrm{CHB}$. The release of mitochondrial inter-membrane proteins into the cytoplasm plays a crucial role in the activation of downstream caspases, triggering DNA fragmentation and chromatin condensation. As shown in Figure 6G-K, cytochrome $\mathrm{c}$ and AIF were released into the cytoplasm in both the cell lines after 24 hours of treatment of CHB. The results imply that CHB-induced apoptosis is closely dependant on the mitochondrial pathway.

\section{Discussion}

MDR has become the largest obstacle to the success of cancer chemotherapies. More number of researches worldwide have been focusing on the identification of MDR reversal agents that can act as supplements to classic chemotherapy agents, which when given in high dosages could cause undesirable pharmacokinetic side effects such as drug-drug interactions and unexpected toxicities. ${ }^{29-31}$ Till date, there are no effective MDR reversal agents employed for cancer treatment in clinical practice. Thus, the other effective way of future MDR therapy will rely on the endeavors to develop novel anti-MDR agents, which can effectively inhibit the proliferation of MDR cancer cells directly. In recent years, some compounds such as PH II-7, SB-T-12843, S9, and IG105 $32-35$ have been found to possess anti-MDR activity. CHB, a major active component extracted from $S$. chamaejasme L., has been found to exhibit potent antiproliferative effects in eight human solid tumor cell lines. ${ }^{20}$ However, it is unclear whether CHB can exhibit the same activity in MDR cell lines, and the mechanism of its action still remains elusive.

First, our data show that CHB is a potent anti-MDR agent in vitro. Compared to four traditional chemotherapeutic agents DOX, TAX, VCR, and 5-FU, CHB was potent not only against sensitive human cancer cell lines but also their corresponding MDR sublines, which were highly resistant to the four traditional agents. The potency against MDR cancer cells indicates that $\mathrm{CHB}$ may have different modes of action when compared to conventional chemotherapeutic agents. Consistently, when VCR inhibited the growth of the xenograft tumor of only KB but not that of KBV200, CHB was effective on both cell lines without a significant loss in host body weight, which suggested that $\mathrm{CHB}$ is tolerable for all the mice during the treatment process. All these results demonstrate that CHB exhibits good anti-MDR activity both in vitro and in vivo.

Deficiency in apoptosis is believed to contribute to cancer initiation, progression, and treatment failure. Here, it was found that G0/G1 phase arrest as well as apoptosis was induced in both sensitive KB and resistant KBV200 cells after CHB exposure. As apoptosis is an important consequence of cell cycle arrest; these phenomena indicate that CHB-induced apoptosis may be cell cycle-dependent, and the activities of CHB against MDR cancer cells can be partially associated with its ability to induce cell cycle arrest and apoptosis in MDR cells.

Resistance to apoptosis may result from the inactivation of pro-apoptotic effectors and activation of anti-apoptotic factors. ${ }^{36}$ Here, we detected the effect of $\mathrm{CHB}$ on intrinsic and extrinsic apoptosis pathways. First, it was found that the expression of Fas, FasL, and procaspase 8 was not remarkably changed in both KB and KBV200 cells after CHB treatment, which indicated that CHB-induced apoptosis was not related to extrinsic Fas/FasL pathway. Subsequent data showed that apoptosis of KB and KBV200 cells induced by $\mathrm{CHB}$ was dependent on the activation of caspase 9 and caspase 3 . These results imply that apoptosis induced by $\mathrm{CHB}$ may be through intrinsic mitochondrial pathway.

Mitochondria play a central role in cell bioenergetics and the cellular intrinsic apoptosis. Mitochondrial outer membrane permeabilization (MOMP) can be triggered during mitochondria-mediated apoptosis, which has been proposed as a "point of no return" of the mitochondrial apoptotic pathway. ${ }^{37}$ Till date, there are two nonexclusive mechanisms explaining how MOMP is induced. As is known, permeability transition pore complex (PTPC), a large protein complex, plays an important role in MOMP. Currently, it is discovered that the major PTPC components are composed of an outer mitochondrial membrane protein, the voltage-dependent anion channel, the mitochondrial benzodiazepine receptor, the adenine nucleotide translocator in inner mitochondrial membrane, and cyclophilin D in the matrix. ${ }^{38}$ Once the PTPC opens, low molecular weight solutes and water enter and result in the rupturing of the outer mitochondrial membrane, mitochondrial matrix swelling, and loss of $\Delta \Psi_{\mathrm{m}}$. Mitochondrial damage resulting 
from MOMP facilitates cytochrome c as well as AIF release into the cytoplasm. ${ }^{39}$ In addition, MOMP can be regulated by Bcl-2 family. Pro-apoptotic gene Bax forms channels in the mitochondrial membrane, which results in the release of cytochrome $\mathrm{c}$ and a number of other larger proteins from the inter-membrane space. Further, cytochrome c forms a complex with procaspase 9, apoptosis-activating factor-1, and ATP. This causes the activation of procaspase 9, which in turn activates procaspase 3 to caspase 3. Caspase 3 activity initiates the final stages of apoptosis, including surface blebbing, cell shrinkage, and chromatin margination. In addition, Bcl-2 and other anti-apoptotic genes block the release of cytochrome $\mathrm{c}$. Bcl-2 over-expression also inhibits necrotic cell death by inhibiting mitochondrial permeability transition. ${ }^{40,41}$ Here, the level of Bax was upregulated while Bcl-2 was downregulated in both KB and KBV200 cells after $\mathrm{CHB}$ treatment, and thus, the ratio of Bax and Bcl-2 was remarkably increased. This suggests that $\mathrm{CHB}$ may increase caspases activity through the regulation of $\mathrm{Bcl}-2$ family members. Thus, the alteration of the pro-apoptotic and anti-apoptotic Bcl-2 family members may be an important mechanism of $\mathrm{CHB}$ on MDR treatment. The data further indicated that $\mathrm{CHB}$ led to the loss of $\Delta \Psi_{\mathrm{m}}$ and the release of cytochrome $\mathrm{c}$ and AIF from mitochondria to cytosol in both KB and KBV200 cells. These phenomena imply that the $\mathrm{CHB}$ may trigger cytochrome $\mathrm{c}$ release by regulating the expression levels of Bcl-2 family proteins and/or their translocation. These data provided additional evidence to prove that $\mathrm{CHB}$-induced apoptosis was through intrinsic mitochondrial pathway. This is consistent with several studies that chemotherapy agents and irradiation trigger tumor cell apoptosis through mitochondrial pathway. ${ }^{42,43}$

\section{Conclusion}

MDR is a complicated multifaceted phenomenon commonly encountered in clinical practice. TCM has supplied valuable material resources for finding novel agents to handle MDR. CHB is a natural cytotoxic biflavonoid obtained from S. chamaejasme L., which exhibits favorable anti-MDR activity in vitro and in vivo. It could induce G0/G1 cell cycle arrest as well as apoptosis in both KB and KBV200 cells. Further studies show that its mechanisms may be associated with initiating intrinsic mitochondrial pathway. Based on these data, CHB is found to be an effective agent in inhibiting the growth of MDR cells, which represents a promising lead compound in MDR cancer therapy. Furthermore, these results also provide additional evidence to use $\mathrm{CHB}$ in the clinical trial for MDR cancer therapy.

\section{Acknowledgments}

This work was supported by Grants from China National Natural Sciences Foundation (No 81303273), National Major Scientific and Technological Special Project for "Significant New Drugs Development" during the Twelfth Five-year Plan Period (No 2013ZX09301307001004), and Optional Research Project sponsored by China Academy of Chinese Medical Science (No ZZ2014058).

\section{Disclosure}

The authors report no conflicts of interest in this work.

\section{References}

1. Kartal-Yandim M, Adan-Gokbulut A, Baran Y. Molecular mechanisms of drug resistance and its reversal in cancer. Crit Rev Biotechnol. 2015;(11):1-11.

2. Wu Q, Yang Z, Nie Y, Shi Y, Fan D. Multi-drug resistance in cancer chemotherapeutics: mechanisms and lab approaches. Cancer Lett. 2006; 347(2):159-166.

3. Szakacs G, Paterson JK, Ludwig JA, Booth-Genthe C, Gottesman MM. Targeting multidrug resistance in cancer. Nat Rev Drug Discov. 2006; 5(3):219-234.

4. Miao ZH, Ding J. [Research advances on circumventing tumor multidrug resistance]. Ai Zheng. 2003;22(8):886-892. Chinese.

5. Eberle J, Fecker LF, Forschner T, Ulrich C, Rowert-Huber J, Stockfleth E. Apoptosis pathways as promising targets for skin cancer therapy. $\mathrm{Br}$ J Dermatol. 2007;156(Suppl 3):18-24.

6. Lock-Andersen J, Horn J, Sjostrand H. [Prognosis after sentinel node biopsy in malignant melanoma]. Ugeskr Laeger. 2006;168(25):2457-2462. Spanish.

7. Kroemer G, Galluzzi L, Brenner C. Mitochondrial membrane permeabilization in cell death. Physiol Rev. 2007;87(1):99-163.

8. Jang MH, Shin MC, Shin HS, et al. Alcohol induces apoptosis in TM3 mouse Leydig cells via bax-dependent caspase-3 activation. Eur J Pharmacol. 2002;449(1-2):39-45.

9. Reed JC. Double identity for proteins of the Bcl-2 family. Nature. 1997; 387(6635):773-776.

10. Fresquet V, Rieger M, Carolis C, Garcia-Barchino MJ, MartinezCliment JA. Acquired mutations in BCL2 family proteins conferring resistance to the BH3 mimetic ABT-199 in lymphoma. Blood. 2014;123(26): 4111-4119.

11. Singh A, Ni J, Aggarwal BB. Death domain receptors and their role in cell demise. J Interferon Cytokine Res. 1998;18(7):439-450.

12. Green DR, Kroemer G. Pharmacological manipulation of cell death: clinical applications in sight? J Clin Invest. 2005;115(10): 2610-2617.

13. Wagner KW, Punnoose EA, Januario T, et al. Death-receptor O-glycosylation controls tumor-cell sensitivity to the proapoptotic ligand Apo2L/TRAIL. Nat Med. 2007;13(9):1070-1077.

14. Wang L, Duan H, Wang Y, et al. Inhibitory effects of Lang-du extract on the in vitro and in vivo growth of melanoma cells and its molecular mechanisms of action. Cytotechnology. 2010;62(4):357-366.

15. Kan XX, Wang ZX, Yang QX, et al. [Antitumor effect of alcohol extracts from Stellera chamaejasme]. Zhongguo Zhong Yao Za Zhi. 2013;38(8): 1219-1225. Chinese.

16. Liu X, Yang Q, Zhang G, et al. Anti-tumor pharmacological evaluation of extracts from Stellera chamaejasme L based on hollow fiber assay. BMC Complement Altern Med. 2012;14:116.

17. Liu X, Li Y, Yang Q, et al. [Comparative study on tumor cell apoptosis in vitro induced by extracts of Stellera chamaejasme]. Zhongguo Zhong Yao Za Zhi. 2012;37(10):1440-1444. Chinese. 
18. Liu X, Li Y, Yang Q, et al. In vitro inhibitory and pro-apoptotic effect of Stellera chamaejasme L extract on human lung cancer cell line NCIH157. J Tradit Chin Med. 2012;32(3):404-410.

19. Liu X, Zhu X. Stellera chamaejasme L. extract induces apoptosis of human lung cancer cells via activation of the death receptor-dependent pathway. Exp Ther Med. 2012;4(4):605-610.

20. Li J, Zhang JJ, Pang XX, ZhengChen XL, Gan LS. Biflavanones with anti-proliferative activity against eight human solid tumor cell lines from Stellera chamaejasme. Fitoterapia. 2014;93:163-167.

21. Yang G, Chen D. Biflavanones, flavonoids, and coumarins from the roots of Stellera chamaejasme and their antiviral effect on hepatitis B virus. Chem Biodivers. 2008;5(7):1419-1424.

22. Liu WK, Cheung FW, Liu BP, Li C, Ye W, Che CT. Involvement of p21 and FasL in induction of cell cycle arrest and apoptosis by neochamaejasmin A in human prostate LNCaP cancer cells. J Nat Prod. 2008;71(5): 842-846.

23. Zhang T, Yu H, Dong G, Cai L, Bai Y. Chamaejasmine arrests cell cycle, induces apoptosis and inhibits nuclear NF-kappaB translocation in the human breast cancer cell line MDA-MB-231. Molecules. 2013;18(1): 845-858.

24. Pan L, Hu H, Wang X, et al. Inhibitory effects of neochamaejasmin B on P-glycoprotein in MDCK-hMDR1 cells and molecular docking of NCB binding in P-glycoprotein. Molecules. 2015;20(2):2931-2948.

25. Zhang $\mathrm{C}$, Zhou SS, Feng LY, et al. In vitro anti-cancer activity of chamaejasmenin B and neochamaejasmin C isolated from the root of Stellera chamaejasme L. Acta Pharmacol Sin. 2013;34(2):262-270.

26. Wang ZX, Cheng MC, Zhang XZ, et al. Cytotoxic biflavones from Stellera chamaejasme. Fitoterapia. 2014;99:334-340.

27. Wang YJ, Chen XG, Xiao ZY, Liu GT, Sun H. Induction of cell cycle arrest by GL331 via triggering an ATM-dependent DNA damage response in HepG2 cells. J Asian Nat Prod Res. 2012;14(7):657-664.

28. Gui M, Shi DK, Huang M, et al. D11, a novel glycosylated diphyllin derivative, exhibits potent anticancer activity by targeting topoisomerase II alpha. Invest New Drugs. 2011;29(5):800-810.

29. Baer MR, George SL, Dodge RK, et al. Phase 3 study of the multidrug resistance modulator PSC-833 in previously untreated patients 60 years of age and older with acute myeloid leukemia: Cancer and Leukemia Group B Study 9720. Blood. 2002;100(4):1224-1232.

30. Stewart A, Steiner J, Mellows G, Laguda B, Norris D, Bevan P. Phase I trial of XR9576 in healthy volunteers demonstrates modulation of P-glycoprotein in CD56+ lymphocytes after oral and intravenous administration. Clin Cancer Res. 2000;6(11):4186-4191.
31. Minderman H, O’Loughlin KL, Pendyala L, Baer MR. VX-710 (biricodar) increases drug retention and enhances chemosensitivity in resistant cells overexpressing P-glycoprotein, multidrug resistance protein, and breast cancer resistance protein. Clin Cancer Res. 2004;10(5): $1826-1834$.

32. Wang YM, Hu LX, Liu ZM, et al. N-(2,6-dimethoxypyridine-3-yl)9-methylcarbazole-3-sulfo-namide as a novel tubulin ligand against human cancer. Clin Cancer Res. 2008;14(19):6218-6227.

33. Zhang $\mathrm{C}$, Yang N, Yang $\mathrm{CH}$, et al. S9, a novel anticancer agent, exerts its anti-proliferative activity by interfering with both PI3K-Akt-mTOR signaling and microtubule cytoskeleton. PLoS One. 2009;4(3):e4881.

34. Ojima I, Slater JC, Michaud E, et al. Syntheses and structure-activity relationships of the second-generation antitumor taxoids: exceptional activity against drug-resistant cancer cells. J Med Chem. 1996;39(20): 3889-3896.

35. Su Y, Cheng X, Tan Y, et al. Synthesis of a dual functional anti-MDR tumor agent $\mathrm{PH}$ II-7 with elucidations of anti-tumor effects and mechanisms. PLoS One. 2012;7(3):e32782.

36. Ma Y, Ding Z, Qian Y, et al. Predicting cancer drug response by proteomic profiling. Clin Cancer Res. 2006;12(15):4583-4589.

37. Fesik SW, Shi Y. Structural biology. Controlling the caspases. Science. 2001;294(5546):1477-1478

38. Mattson MP, Chan SL. Calcium orchestrates apoptosis. Nat Cell Biol. 2003;5(12):1041-1043.

39. Dejean LM, Martinez-Caballero S, Kinnally KW. Is MAC the knife that cuts cytochrome $\mathrm{c}$ from mitochondria during apoptosis? Cell Death Differ. 2006;13(8):1387-1395.

40. Jaeschke H, Lemasters JJ. Apoptosis versus oncotic necrosis in hepatic ischemia/reperfusion injury. Gastroenterology. 2003;125(4):1246-1257.

41. Dejean LM, Ryu SY, Martinez-Caballero S, Teijido O, Peixoto PM, Kinnally KW. MAC and Bcl-2 family proteins conspire in a deadly plot. Biochim Biophys Acta. 2006;1797(6-7):1231-1238.

42. Weng CJ, Yang YT, Ho CT, Yen GC. Mechanisms of apoptotic effects induced by resveratrol, dibenzoylmethane, and their analogues on human lung carcinoma cells. J Agric Food Chem. 2009;57(12):5235-5243.

43. Hung JY, Hsu YL, Ni WC, et al. Oxidative and endoplasmic reticulum stress signaling are involved in dehydrocostuslactone-mediated apoptosis in human non-small cell lung cancer cells. Lung Cancer. 2010;68(3): $355-365$.

\section{Publish your work in this journal}

Drug Design, Development and Therapy is an international, peerreviewed open-access journal that spans the spectrum of drug design and development through to clinical applications. Clinical outcomes, patient safety, and programs for the development and effective, safe, and sustained use of medicines are a feature of the journal, which has also been accepted for indexing on PubMed Central. The manuscript management system is completely online and includes a very quick and fair peer-review system, which is all easy to use. Visit http://www.dovepress.com/testimonials.php to read real quotes from published authors. 